\title{
Optimum dynamic characteristic control approach for building mass damper design
}

\author{
Shiang-Jung Wang ${ }^{1,2}$ (D) | Bo-Han Lee ${ }^{2}$ | Wei-Chu Chuang ${ }^{3}$ | Kuo-Chun Chang ${ }^{4}$
}

\begin{abstract}
${ }^{1}$ National Taiwan University of Science and Technology, Department of Civil and Construction Engineering, Taipei, Taiwan

${ }^{2}$ National Center for Research on Earthquake Engineering, Taipei, Taiwan

${ }^{3}$ University of Michigan, Department of Civil and Environmental Engineering, Ann Arbor, MI, U.S.A.

${ }^{4}$ National Taiwan University, Department of Civil Engineering, Taipei, Taiwan
\end{abstract}

\section{Correspondence}

Shiang-Jung Wang, National Taiwan University of Science and Technology, 43 Section 4, Keelung Road, Taipei, Taiwan. Email: sjwang@ncree.narl.org.tw

\section{Funding information}

Ministry of Science and Technology, Grant/Award Number: MOST, 102-2221E-002-127-

\begin{abstract}
Summary
A new seismic design manner, namely building mass damper (BMD), which is inspired from a combination of mid-story isolation and tuned mass damper design concepts, recently attracts immense attention. It is mainly because that the use of partial structural mass of the building as an energy absorber in the BMD design can overcome the drawback of limited response reduction due to insufficient added tuned mass in the conventional tuned mass damper design. In this study, an optimum BMD (OBMD) design approach, namely optimum dynamic characteristic control approach, based on a simplified 3-lumped-mass structure model is proposed to seismically protect both the superstructure (or tuned mass) and the substructure (or primary structure), respectively, above and below the control layer. A series of sensitivity analyses and experimental studies on different parameters, including mass, frequency, and damping ratios, of a building model designed with a BMD system were conducted. The test results verify the practical feasibility of the BMD concept as well as the effectiveness of the proposed OBMD design. Furthermore, by comparing with the numerical results of a mid-story isolated counterpart, it is demonstrated that the proposed OBMD design can have a comparable and even better control performance.
\end{abstract}

\section{KEYWORDS}

building mass damper, optimum design, seismic performance, sensitivity analysis, shaking table test

\section{1 | INTRODUCTION}

The excellent performance of seismically isolated buildings during past earthquakes has encouraged the adoption of seismic isolation technology for structural and non-structural protection..$^{1-3}$ Among the increasing practical applications, the mid-story isolation design, in which the isolation system is usually installed on the top of the first story of a building, is recently gaining popularity owing to its advantages in terms of construction efficiency, space use, and maintenance over the conventional base isolation design. ${ }^{4,5}$ The seismic performance of mid-story isolated buildings has been thoroughly investigated. ${ }^{4-8}$ It was indicated that the mid-story isolation design is effective in reducing the seismic demand of the superstructure (SUP) above the isolation system if the coupling of higher modes is precluded. However, due to the flexibility of the substructure (SUB) and the contribution of higher modes, the seismic response of the SUB below the isolation system may be enlarged.

On the other hand, the use of tuned mass dampers (TMDs) as a means to control the dynamic response of the attached structure was first proposed by Frahm. ${ }^{9}$ It has been recognized as an effective passive energy absorbing device to reduce the undesirable oscillation of the attached vibrating system (or primary system) subjected to harmonic excitation. ${ }^{10-12}$ A typical TMD system is essentially consisting of a tuned absorber mass, a spring, and a dashpot. Based on a simplified 
2-lumped-mass structure model, various approaches for selecting the optimum design parameters of a TMD system have been developed by means of generating a phase lag attributed to resonance between the primary and TMD systems. For instance, to minimize the steady-state response of the primary system, Den Hartog ${ }^{10}$ derived the closed-form solutions for the optimum tuning frequency and damping ratio of a TMD system attached to an undamped system under harmonic excitation. Afterward, Warburton ${ }^{13}$ studied the optimum TMD design parameters for an undamped system subjected to harmonic external force and white-noise random excitation. However, all systems contain some damping in reality. Tsai and $\operatorname{Lin}^{14}$ studied the optimum TMD design parameters for a damped system by numerical iteration and curve-fitting procedures. Villaverde ${ }^{15}$ derived and numerically demonstrated that a TMD system can perform effectively subjected to seismic loading when the 2 complex modes of vibration have approximately the same modal damping ratios as the average of the damping ratios of the primary and TMD systems. However, Sadek ${ }^{16}$ found that it is valid only for mass ratios smaller than 0.005 and the difference is more significant when the mass ratio becomes larger. Accordingly, Sadek's proposed criterion ${ }^{16}$ for seismic application was to select, for a given mass ratio, the tuning frequency and damping ratio that would result in equally large modal damping in the 2 complex modes of vibration.

The TMD design concept was first adopted to mitigate the wind-induced vibration or enhance the serviceability of high-rise buildings, ${ }^{17,18}$ and was subsequently adopted to enhance the seismic capability of building structures. ${ }^{19-22}$ Until now, the effectiveness of the TMD design in reducing structural responses subjected to seismic loading is still arguable, especially when the tuned mass is much lighter than the primary structure. To overcome the concern of limited response reduction due to insufficient tuned mass in the conventional TMD design, a new design concept, namely building mass damper (BMD) or self mass damper, was proposed and numerically studied. ${ }^{23-25}$ In the BMD system, as implied in the name, a part of structural mass, instead of additional mass, is intended to be an energy absorber. Ziyzeifar and Noguchi ${ }^{23}$ utilized an isolation layer composed of elastic bearings and viscous dampers to isolate a part of the structure in a tall building for versatile design goals. One of the goals was to reduce the seismic response of the SUB below the isolation layer by means of significant and out-of-phase movement of the isolated SUP as a vibration absorber together with additional damping contributed by viscous dampers. In addition, based on the numerical results of a 13-story building subjected to various seismic excitation, Villaverde ${ }^{24}$ indicated that the insertion of flexible laminated rubber bearings and viscous dampers between the roof and the rest of the building, namely roof isolation system, can effectively reduce the seismic response of the building. That is, the roof isolation system was designed to be a vibration absorber. These studies also disclosed that the isolated SUP or the roof isolation system as a vibration absorber is practically feasible for both new construction and retrofit purposes.

The BMD concept has been applied to a few new construction and retrofitted buildings; for instance, the Swatch Group Japan Headquarter ${ }^{26}$ and Mita Bellju Building in Tokyo as well as the Theme Building at the Los Angeles International Airport. ${ }^{27}$ However, among these applications, the control target was still mainly focused on the SUB (or primary structure) performance rather than on either the SUP (or tuned mass) performance or both. If the SUP in the BMD design is intended to be used for occupancy as the SUB, excessive dynamic responses are not acceptable definitely. Under this circumstance, the seismic performance of both the SUB and SUP should be paid attention.

In this study, to combine the advantages of seismic isolation and TMD designs, an optimum design method for a BMD system is investigated. A building structure designed with a BMD system is rationally assumed to be represented by a simplified 3-lumped-mass structure model, composed of the SUP, control layer (CL), and SUB. Referring to Sadek's research, ${ }^{16}$ the objective function is refined as that 3 modal damping ratios obtained from the simplified structure model in the direction of interest are equally important and taken as an approximately equal value. Accordingly, the optimum BMD (OBMD) design parameters can be rationally determined based on the proposed optimum dynamic characteristic control approach. First, the influences of varied mass ratios and inherent damping ratios on the OBMD design parameters are quantitatively discussed. Then, a series of shaking table tests were performed to verify the feasibility of the BMD concept as well as the effectiveness of the proposed OBMD design on seismic protection of the building models. Finally, the test results of the OBMD design are compared with the numerical results of a mid-story isolated counterpart to further demonstrate the potential advantage of the proposed OBMD design over the mid-story isolation design.

\section{2 | ANALYTICAL STUDY}

\section{1 | Simplified 3-lumped-mass structure model}

In this study, the BMD system is intended to be installed upon a multi-story SUB (or primary structure). The system is essentially composed of a multi-story SUP (or tuned mass) as well as spring and dashpot elements for connecting the 
SUP to the SUB. The stiffness and damping designed for the BMD system, of course, are provided by the spring and dashpot elements, respectively. A simplified 3-lumped-mass structure model, in which the 3 lumped mass are, respectively, assigned at the SUP, CL, and SUB, is rationally assumed to represent a building structure designed with a BMD system, as shown in Figure 1, to comprehensively account for the dynamic characteristics of both the SUB and SUP. To be precise, the SUP and $\mathrm{CL}$ are not assumed to vibrate as a rigid body in this simplified structure model. For doing so, an excessive (or unreasonable) damping demand for the OBMD design owing to a significant SUP-to-SUB mass ratio and neglect of flexibility of the SUP can be precluded, which will be further discussed in Section 2.3.

The equation of motion for the simplified structure model in the horizontal direction can be written as

$$
\begin{aligned}
& \mathbf{M u} \ddot{+} \mathbf{C u}+\mathbf{K u}=\mathbf{M R} \ddot{u}_{g} \\
& \Rightarrow\left[\begin{array}{ccc}
m_{1} & 0 & 0 \\
0 & m_{2} & 0 \\
0 & 0 & m_{3}
\end{array}\right]\left\{\begin{array}{l}
\ddot{u}_{1} \\
\ddot{u}_{2} \\
\ddot{u}_{3}
\end{array}\right\}+\left[\begin{array}{ccc}
c_{1}+c_{2} & -c_{2} & 0 \\
-c_{2} & c_{2}+c_{3} & -c_{3} \\
0 & -c_{3} & c_{3}
\end{array}\right]\left\{\begin{array}{l}
\dot{u}_{1} \\
\dot{u}_{2} \\
\dot{u}_{3}
\end{array}\right\} \\
& +\left[\begin{array}{ccc}
k_{1}+k_{2} & -k_{2} & 0 \\
-k_{2} & k_{2}+k_{3} & -k_{3} \\
0 & -k_{3} & k_{3}
\end{array}\right]\left\{\begin{array}{l}
u_{1} \\
u_{2} \\
u_{3}
\end{array}\right\}=-\left[\begin{array}{ccc}
m_{1} & 0 & 0 \\
0 & m_{2} & 0 \\
0 & 0 & m_{3}
\end{array}\right]\left\{\begin{array}{l}
1 \\
1 \\
1
\end{array}\right\} \ddot{u}_{g}
\end{aligned}
$$

where $\mathbf{M}=$ the generalized seismic reactive mass matrix; $m_{1}, m_{2}$, and $m_{3}=$ the generalized seismic reactive masses for the fundamental mode of vibration computed for a unit modal participation factor of the SUB, CL, and SUP, respectively; $\mathbf{K}$ and $\mathbf{C}=$ the horizontal generalized stiffness and damping coefficient matrices, respectively; $k_{1}\left(c_{1}\right), k_{2}\left(c_{2}\right)$, and $\mathrm{k}_{3}\left(c_{3}\right)$ $=$ the horizontal stiffness (viscous damping coefficients) for the fundamental mode of vibration of the SUB, CL, and SUP, respectively; $\mathbf{u}=$ the horizontal displacement vector relative to ground; $u_{1}, u_{2}$, and $u_{3}=$ the horizontal displacements of the SUB, CL, and SUP relative to ground, respectively; $\ddot{u}_{g}=$ the horizontal ground acceleration; and $\mathbf{R}=$ the earthquake influence vector.

The equation of motion given in Equation 1 can also be expressed in terms of the nominal frequency $\omega_{1}$, frequency (or tuning) ratio $f_{i}(i=2,3)$, mass ratio $\mu_{i}(i=2,3)$, and component damping ratio $\xi_{i}(i=1$ to 3$)$, as defined in the following

$$
\begin{gathered}
f_{i}=\frac{\omega_{i}}{\omega_{1}}, i=2,3 \\
\mu_{i}=\frac{m_{i}}{m_{1}}, i=2,3 \\
\xi_{i}=\frac{c_{i}}{2 \sum_{j=i}^{3} m_{j} \omega_{i}}, i=1 \text { to } 3
\end{gathered}
$$

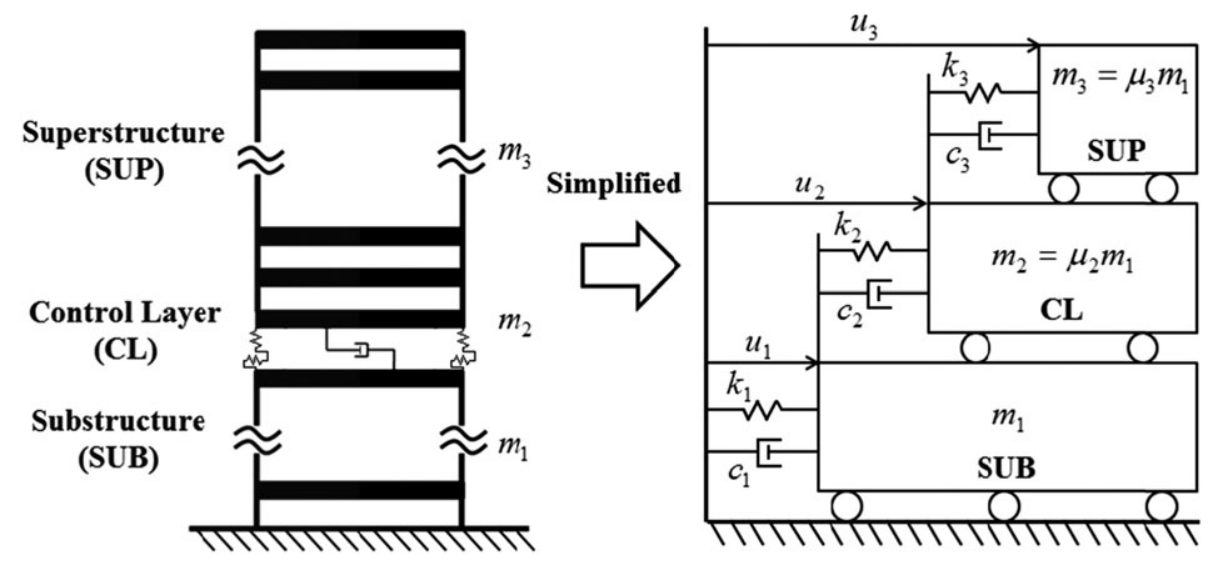

FIGURE 1 Simplified 3-lumped-mass structure model for BMD design 
where $i$ and $j=1,2$, and 3 denote the SUB, CL, and SUP, respectively; and the nominal frequencies $\omega_{1}, \omega_{2}$, and $\omega_{3}$ are defined as $\sqrt{k_{1} / m_{1}}, \sqrt{k_{2} /\left(m_{2}+m_{3}\right)}$, and $\sqrt{k_{3} / m_{3}}$, respectively.

\subsection{Optimum design method based on modal characteristic control concept}

By means of the state space method under coupling approximation, the system matrix $\mathbf{A}$ for Equation 1 can be obtained as follows

$$
\mathbf{A}=\left[\begin{array}{cc}
\mathbf{0} & \mathbf{I} \\
-\mathbf{M}^{-1} \mathbf{K} & -\mathbf{M}^{-1} \mathbf{C}
\end{array}\right]=\left[\begin{array}{cccccc}
0 & 0 & 0 & 1 & 0 & 0 \\
0 & 0 & 0 & 0 & 1 & 0 \\
0 & 0 & 0 & 0 & 0 & 1 \\
a_{41} & a_{42} & 0 & a_{44} & a_{45} & 0 \\
a_{51} & a_{52} & a_{53} & a_{54} & a_{55} & a_{56} \\
0 & a_{62} & a_{63} & 0 & a_{65} & a_{66}
\end{array}\right]
$$

where $\mathbf{0}$ is the zero matrix; $\mathbf{I}$ is the identity matrix; $a_{41}=-\omega_{1}^{2}\left[1+f_{2}^{2}\left(\mu_{2}+\mu_{3}\right)\right] ; a_{42}=\omega_{1}^{2} f_{2}^{2}\left(\mu_{2}+\mu_{3}\right) ; a_{44}=$ $-2 \omega_{1}\left[\left(\xi_{1}+f_{2} \xi_{2}\right)\left(\mu_{2}+\mu_{3}\right)+\xi_{1}\right] ; \quad a_{45}=2 \omega_{1} f_{2} \xi_{2}\left(\mu_{2}+\mu_{3}\right) ; \quad a_{51}=\omega_{1}^{2} f_{2}^{2}\left(\mu_{2}+\mu_{3}\right) / \mu_{2} ; \quad a_{52}=-\omega_{1}^{2}\left[f_{2}{ }^{2}\left(\mu_{2}+\mu_{3}\right)+f_{3}^{2} \mu_{3}\right] / \mu_{2} ;$ $a_{53}=\omega_{1}^{2} f_{3}^{2} \mu_{3} / \mu_{2} ; a_{54}=2 \omega_{1} f_{2} \xi_{2}\left(\mu_{2}+\mu_{3}\right) / \mu_{2} ; a_{55}=-2 \omega_{1}\left[f_{2} \xi_{2}\left(\mu_{2}+\mu_{3}\right)+f_{3} \xi_{3} \mu_{3}\right] / \mu_{2} ; a_{56}=2 \omega_{1} f_{3} \xi_{3} \mu_{3} / \mu_{2} ; a_{62}=\omega_{1}^{2} f_{3}^{2} ; a_{63}=$ $-\omega_{1}^{2} f_{3}^{2} ; a_{65}=2 \omega_{1} f_{3} \xi_{3} ;$ and $a_{66}=-2 \omega_{1} f_{3} \xi_{3}$.

The complex eigenvalues of Equation 5 can be calculated in a form of conjugate pairs as follows

$$
\lambda_{2 n-1,2 n}^{\prime}=\omega_{n}^{\prime} \xi_{n}^{\prime} \pm i \omega_{n}^{\prime} \sqrt{1-\xi_{n}^{\prime} 2}, n=1,2,3
$$

where $\lambda_{2 n-1}^{\prime}$ is the $n^{\text {th }}$ modal eigenvalue of the system; $\lambda_{2 n}^{\prime}$ is the conjugate of $\lambda_{2 n-1}^{\prime} ; \omega_{n}^{\prime}$ and $\xi_{n}^{\prime}$ are the $n^{\text {th }}$ modal natural frequency and the $n^{\text {th }}$ modal damping ratio of the system, respectively; and $i$ is the unit imaginary number (ie, $i=\sqrt{-1}$ ).

The proposed objective function to determine the OBMD design parameters in this study is modified from Sadek's research. ${ }^{16}$ That is, the modal damping ratios in the 3 complex modes of vibration are equally important and are taken as an approximately equal value, ie, $\xi_{1} \cong \xi_{2} \cong \xi_{3}$. Scientifically and reasonably, this control principle intends to simultaneously mitigate the dynamic responses of the SUB, CL, and SUP in the direction of interest. Meanwhile, it would also result in approximately equal modal natural frequencies in the 3 complex modes of vibration. ${ }^{16}$ This objective function, conceptually, is similar to the pole placement control, ${ }^{28}$ which can be easily achieved by applying additional active control force. However, this study aims at a passive control approach. It is impossible to have 3 perfectly equal modal natural frequencies by only applying passive control force. Three approximately equal modal damping ratios in this study are determined based on the minimum sum of differences of each 2 complex eigenvalues (or modal damping ratios, or modal natural frequencies), as shown in Figure 2. By means of the proposed objective function with given $\omega_{1}, \mu_{2}, \mu_{3}$, $\xi_{1}$, and $\xi_{3}$, the optimum design parameters for $f_{2}, f_{3}$, and $\xi_{2}$, ie, $f_{2}^{\text {opt }}, f_{3}^{\text {opt }}$, and $\xi_{2}^{\text {opt }}$, respectively, can be determined.

FIGURE 2 Illustration of minimum sum of differences of each 2 complex eigenvalues (or modal damping ratios, or modal natural frequencies)
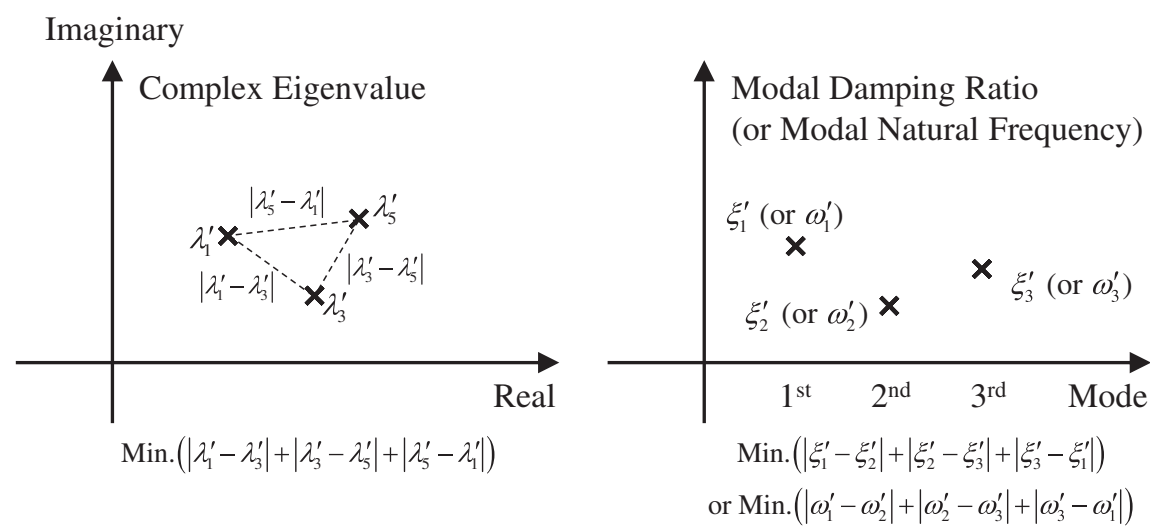


\subsection{Sensitivity analysis considering varied mass and damping ratios}

Assume that the mass ratios $\mu_{2}$ and $\mu_{3}$ vary within a reasonable range, respectively, from 0.1 (ie, basically representing a high-rise SUB) to 0.5 (ie, basically representing a low-rise SUB) and 0.1 (ie, basically representing a low-rise SUP) to 2 (ie, the story number of the SUP is twice as many as that of the SUB), as illustrated in Figure 3. Besides, assume that both $\xi_{1}$ and $\xi_{3}$ are set to be $2 \%$ and $10 \%$ to correspondingly represent a bare structure and a structure with additional damping devices. Therefore, on the basis of the proposed objective function, the optimum damping ratio $\xi_{2}^{\text {opt }}$ and the optimum frequency (or tuning) ratios $f_{2}^{o p t}$ and $f_{3}^{\text {opt }}$ for the OBMD design varying with different $\mu_{2}, \mu_{3}, \xi_{1}$, and $\xi_{3}$ are calculated and shown in Figure 4. It can be seen from the figure that the optimum design parameters $\xi_{2}^{o p t}, f_{2}^{o p t}$, and $f_{3}^{o p t}$, in general, are proportional to $\mu_{2}$ and are inversely proportional to $\mu_{3}$. This trend is less significant when $\mu_{2}$ and $\mu_{3}$ become larger gradually. It is implied that a decrease of $\mu_{2}$ and an increase of $\mu_{3}$ may reduce the OBMD design demands, including the damping and frequency (or tuning) ratios. In addition, the optimum damping ratio $\xi_{2}^{\text {opt }}$ will increase when $\xi_{1}$ is increased and will decrease when $\xi_{3}$ is increased. For the optimum frequency ratios, increasing $\xi_{3}$ will lead to an increased demand of $f_{2}^{\text {opt }}$ while will reduce the demand of $f_{3}^{\text {opt }}$. On the other hand, the variation of the optimum frequency ratios with different $\xi_{1}$

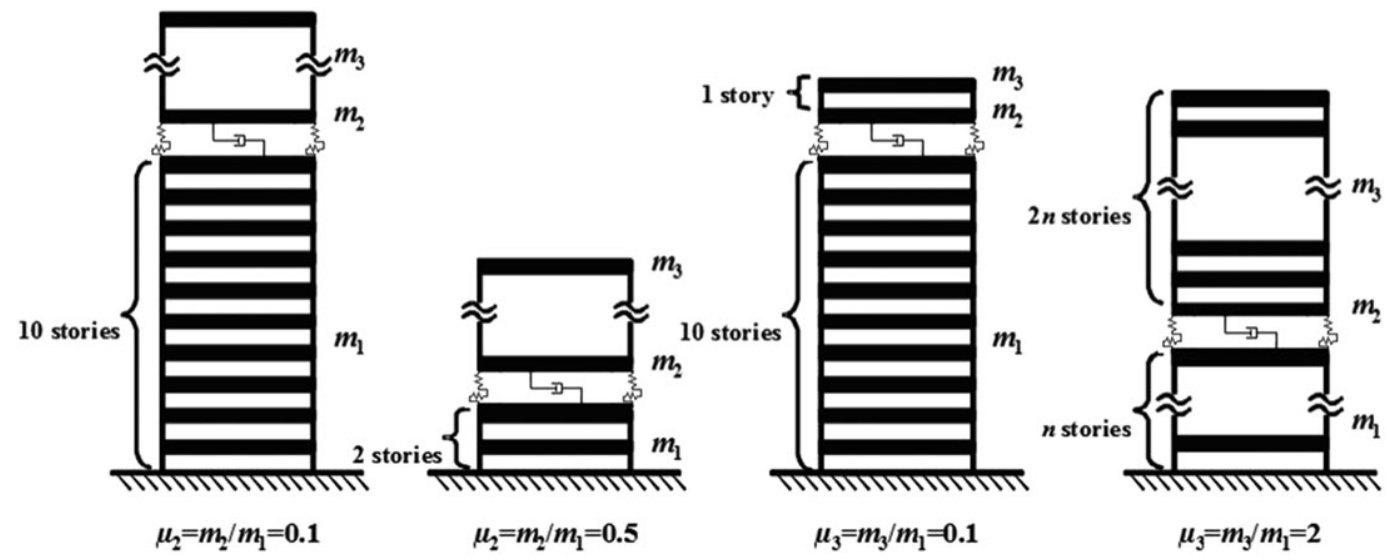

FIGURE 3 Variation ranges of $\mu_{2}$ and $\mu_{3}$ for sensitivity analysis
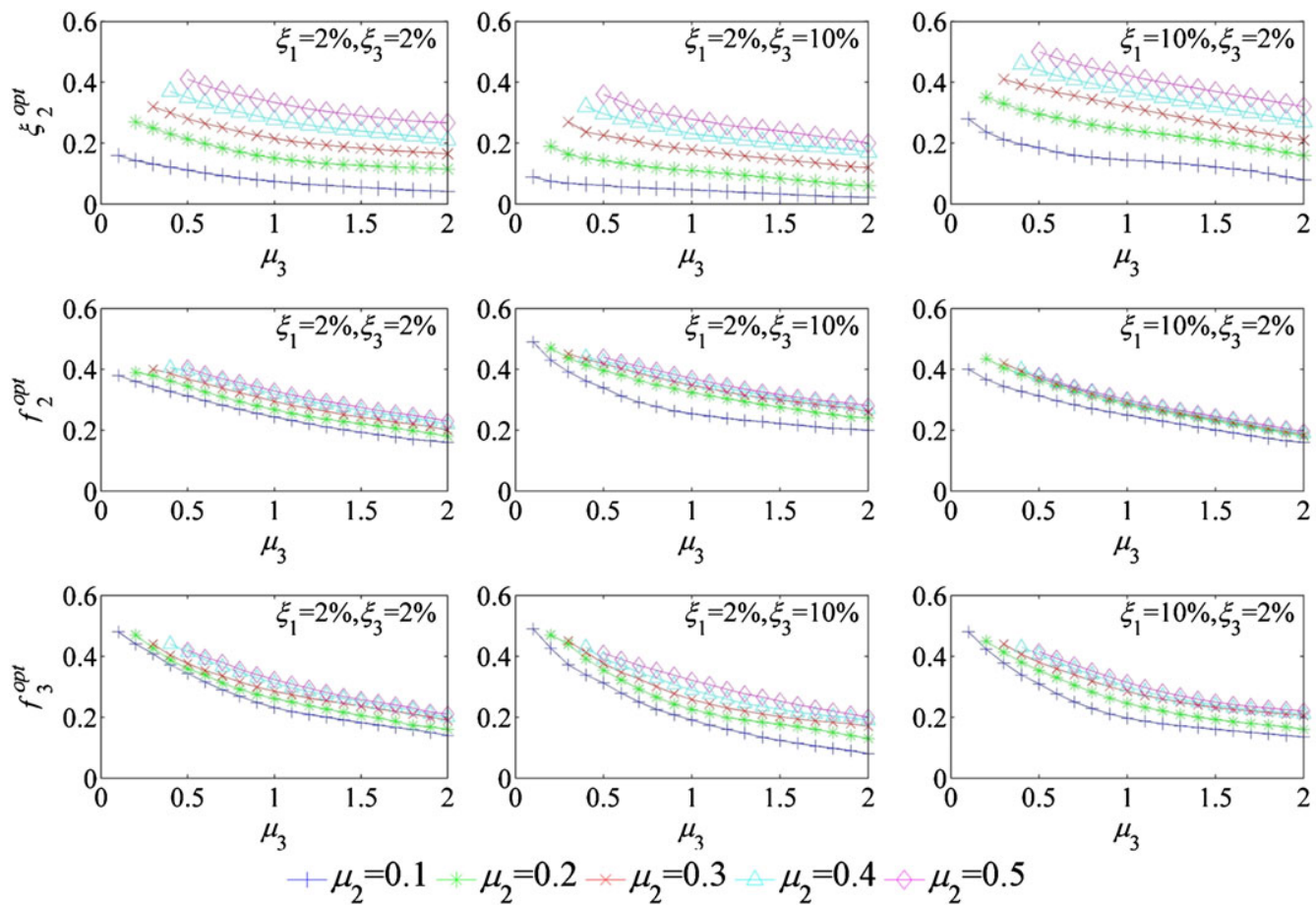

FIGURE $4 \xi_{2}^{o p t}, f_{2}^{o p t}$, and $f_{3}^{o p t}$ varying with respect to $\mu_{2}, \mu_{3}, \xi_{1}$, and $\xi_{3}$ [Colour figure can be viewed at wileyonlinelibrary.com] 
is very sensitive to the mass ratios. When $\xi_{1}$ is increased, the demand of $f_{2}^{\text {opt }}$ will generally decrease except for the nearly same trend at $\mu_{2}$ equal to 0.1 , and the demand of $f_{3}^{\text {opt }}$ will decrease if $\mu_{2}$ is small and will increase slightly with larger $\mu_{2}$.

In Sadek's research ${ }^{16}$ and many past studies relevant to the TMD design, a simplified 2-lumped-mass structure model was usually utilized to study the optimum TMD design parameters. Under this circumstance, only 1 mass ratio, ie, a total of $\mu_{2}$ and $\mu_{3}$, was required to be defined. By comparing the results shown in Figure 5 to those obtained from Sadek's study, obviously, the sensitivities of $f_{2}^{\text {opt }}$ and $\xi_{2}^{\text {opt }}$, respectively, varying with different $\mu_{2}$ and $\mu_{3}$ based on the simplified 3-lumped-mass structure model have very different tendencies from those of the optimum design results varying with different mass and damping ratios based on the simplified 2-lumped-mass structure model.

It was rarely concerned whether the damping demand is reasonable and practicable if the mass ratio of the TMD design becomes larger. The following is a simple quantitative comparison between the optimum damping ratios obtained by using the simplified 2-lumped-mass and 3-lumped-mass structure models based on a scientific background. As shown in Figure 5, the dotted line represents the trend of the optimum damping ratio varying with respect to the mass ratio when using the simplified 2-lumped-mass structure model and Sadek's proposed criterion (the inherent damping ratio is assumed to be $2 \%$ ). It is found that the optimum damping ratio is proportional to the mass ratio, ie, the larger the mass ratio, the higher the damping demand required. For instance, when the mass ratio reaches to 1, the damping demand is up to $72 \%$, which might not be very reasonable and practicable. As also shown in Figure 5, the solid lines represent the variation of the optimum damping ratio with different combinations of $\mu_{2}$ and $\mu_{3}$ when using the simplified 3-lumped-mass structure model and the proposed optimum dynamic characteristic control approach $\left(\xi_{1}=\xi_{3}=2 \%\right)$. Apparently, an opposite tendency that the optimum damping ratio, in general, is inversely proportional to the total of $\mu_{2}$ and $\mu_{3}$ but proportional to $\mu_{2}$ is observed. More importantly, a more reasonable and applicable damping demand can be obtained especially when $\mu_{2}$ becomes smaller. For instance, when the mass ratio reaches to 1 and $\mu_{2}=0.1$, the damping demand is approximately $22 \%$.

\section{3 | SEISMIC SIMULATION TESTS}

\section{1 | Test structure models}

The bare specimen was designed to be a 1/4 scaled 8-story steel structure model with single-bay widths of 1.5 and $1.1 \mathrm{~m}$, respectively, in the $\mathrm{X}$ and $\mathrm{Y}$ directions, as shown in Figure 6A. Each floor was $1.1 \mathrm{~m}$ high, and each slab was $20 \mathrm{~mm}$ thick. The columns and beams were wide flange with a sectional dimension of $100 \times 100 \times 6 \times 8(\mathrm{~mm})$ and channel with a sectional dimension of $100 \times 50 \times 5 \times 5(\mathrm{~mm})$, respectively. Additional live load of $0.5 \mathrm{kN}-\mathrm{s}^{2} / \mathrm{m}$ simulated by mass blocks with a regular plane arrangement was assigned at each floor.

Apart from the bare specimen, the BMD specimens were designed with a CL at the fourth floor, as shown in Figure 6 B. In other words, the SUB (or primary structure) and SUP (or tuned mass) were 3-story and 4-story structure models, respectively. In this study, for simplicity and practical feasibility, elastomeric bearings (RBs) with a diameter of $180 \mathrm{~mm}$ and linear fluid viscous dampers (FVDs) were rationally adopted to play the roles of spring and dashpot

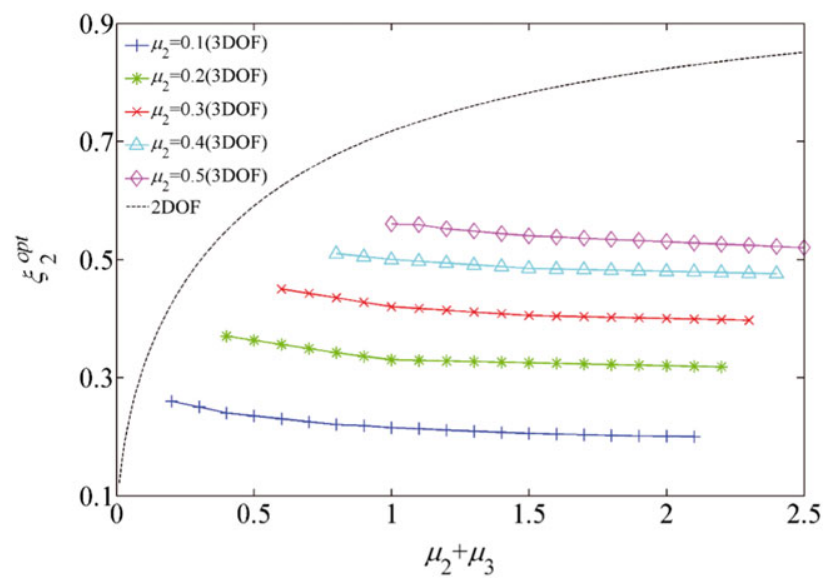

FIGURE 5 Optimum damping ratios obtained by using simplified 2-lumped-mass and 3-lumped-mass structure models [Colour figure can be viewed at wileyonlinelibrary.com] 


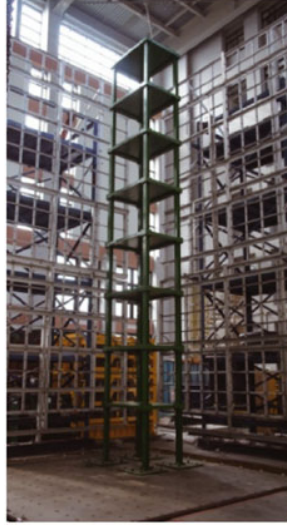

(A) Bare specimen

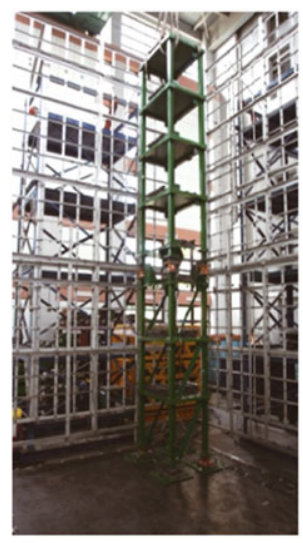

(B) BMD specimen

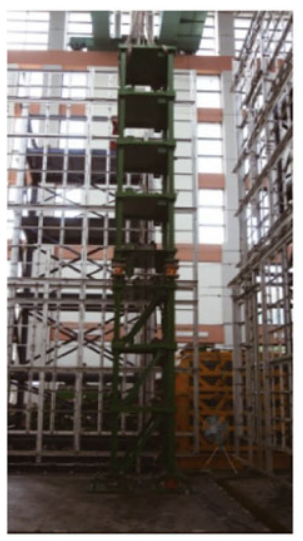

(C) OBMD specimen

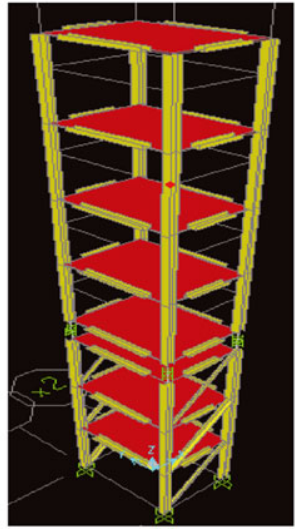

(D) MSI model

FIGURE 6 Experimental and numerical structure models [Colour figure can be viewed at wileyonlinelibrary.com]

elements at the CL, respectively. A series of BMD specimens, ie, BMD-1 to BMD-7 as given in Table 1, were designed to further discuss the influence of varying design parameters on their seismic performance. BMD-2, BMD-1, and BMD-3, the first-group specimens, were intended to only have different $f_{2}$ values in ascending order, but the other design parameters remained the same. To this end, RBs and linear FVDs with different properties as detailed in Table 1 were designed for these 3 specimens. BMD-4, BMD-1, and BMD-5, the second-group specimens, were intended to only have different $f_{3}$ values in ascending order. To this end, angle-section steel braces with different sectional dimensions were installed at the SUB, and accordingly RBs and linear FVDs with different properties were designed for these 3 specimens, as detailed in Table 1. BMD-6, BMD-1, and BMD-7, the third-group specimens, were intended to only have different $\xi_{2}$ values in ascending order by changing the damping coefficients of linear FVDs, as detailed in Table 1.

The modal characteristics of the 8-story bare specimen, 3-story SUB, and 4-story SUP were experimentally identified under white noise excitation, as summarized in Table 2. After obtaining the realistic characteristics, the optimum design parameters $f_{2}^{o p t}, f_{3}^{o p t}$, and $\xi_{2}^{o p t}$ for the OBMD specimen as shown in Figure 6C can be designed according to the proposed objective function with known $\omega_{1}, \mu_{2}, \mu_{3}, \xi_{1}$, and $\xi_{3}$, as detailed in Table 1 .

\section{2 | Earthquake inputs}

Four recorded ground motions with various peak ground acceleration (PGA) levels were selected for the earthquake inputs of the uniaxial shaking table tests (ie, along the $\mathrm{X}$ direction of the specimens), as summarized in Table 3 . They

TABLE 1 Design parameters for all test and numerical structure models

\begin{tabular}{|c|c|c|c|c|c|c|c|}
\hline $\begin{array}{l}\text { Specimen } \\
\text { (Model) }\end{array}$ & $\begin{array}{l}\xi_{2} \\
(\%)\end{array}$ & $f_{2}$ & $f_{3}$ & $\begin{array}{l}\text { Total Stiffness at CL } \\
\text { or Mid-Story Isolation } \\
\text { Layer (4 Sets of RBs) } \\
(\mathrm{kN} / \mathrm{m})\end{array}$ & $\begin{array}{l}\text { Total Rubber } \\
\text { Thickness of } \\
\text { each RB } \\
(\mathrm{mm})\end{array}$ & $\begin{array}{l}\text { Total Damping Coefficient } \\
\text { at CL or Mid-Story Isolation } \\
\text { Layer ( } 2 \text { Sets of FVDs) } \\
(\mathrm{kN}-\mathrm{s} / \mathrm{m})\end{array}$ & $\begin{array}{l}\text { Sectional } \\
\text { Dimension of Added } \\
\text { Braces at SUB } \\
(\mathrm{mm})\end{array}$ \\
\hline BMD-1 & 22 & 0.28 & 0.25 & 3810.28 & 27 & 51.12 & $\mathrm{~L} 70 \times 70 \times 6(\mathrm{SUB})$ \\
\hline BMD-2 & 22 & 0.19 & 0.25 & 1740.52 & 19 & 34.56 & $\mathrm{~L} 70 \times 70 \times 6(\mathrm{SUB})$ \\
\hline BMD-4 & 22 & 0.28 & 0.22 & 4905.20 & 20 & 58.00 & $\mathrm{~L} 90 \times 90 \times 9(\mathrm{SUB})$ \\
\hline BMD-5 & 22 & 0.28 & 0.28 & 3247.72 & 30 & 47.20 & $\mathrm{~L} 60 \times 60 \times 5(\mathrm{SUB})$ \\
\hline BMD-6 & 9 & 0.28 & 0.25 & 3810.28 & 27 & 20.92 & $\mathrm{~L} 70 \times 70 \times 6(\mathrm{SUB})$ \\
\hline BMD-7 & 35 & 0.28 & 0.25 & 3810.28 & 27 & 81.34 & $\mathrm{~L} 70 \times 70 \times 6(\mathrm{SUB})$ \\
\hline
\end{tabular}


TABLE 2 Identified modal characteristics of test specimens

\begin{tabular}{llll} 
Bare Specimen & & & \\
\hline Modal Characteristics & First Mode & Second Mode & Third Mode \\
Natural period & $0.61 \mathrm{sec}$ & $0.18 \mathrm{~s}$ & $0.09 \mathrm{~s}$ \\
Participation mass ratio & $76 \%$ & $12 \%$ & $5 \%$ \\
Three-Story Substructure & & & Third Mode \\
\hline Modal Characteristics & First Mode & Second Mode & $0.03 \mathrm{~s}$ \\
\hline Natural period & $0.21 \mathrm{~s}$ & $0.06 \mathrm{~s}$ & $3 \%$ \\
\hline Participation mass ratio & $84 \%$ & $9 \%$ & \\
\hline Four-Story Superstructure & & Second Mode & $0.08 \mathrm{~s}$ \\
\hline Modal Characteristics & First Mode & $11 \%$ & $4 \%$ \\
\hline Natural period & $0.27 \mathrm{~s}$ & $81 \%$ & Third Mode \\
\hline Participation mass ratio & & & $0.04 \mathrm{~s}$ \\
\hline
\end{tabular}

TABLE 3 Earthquake input program

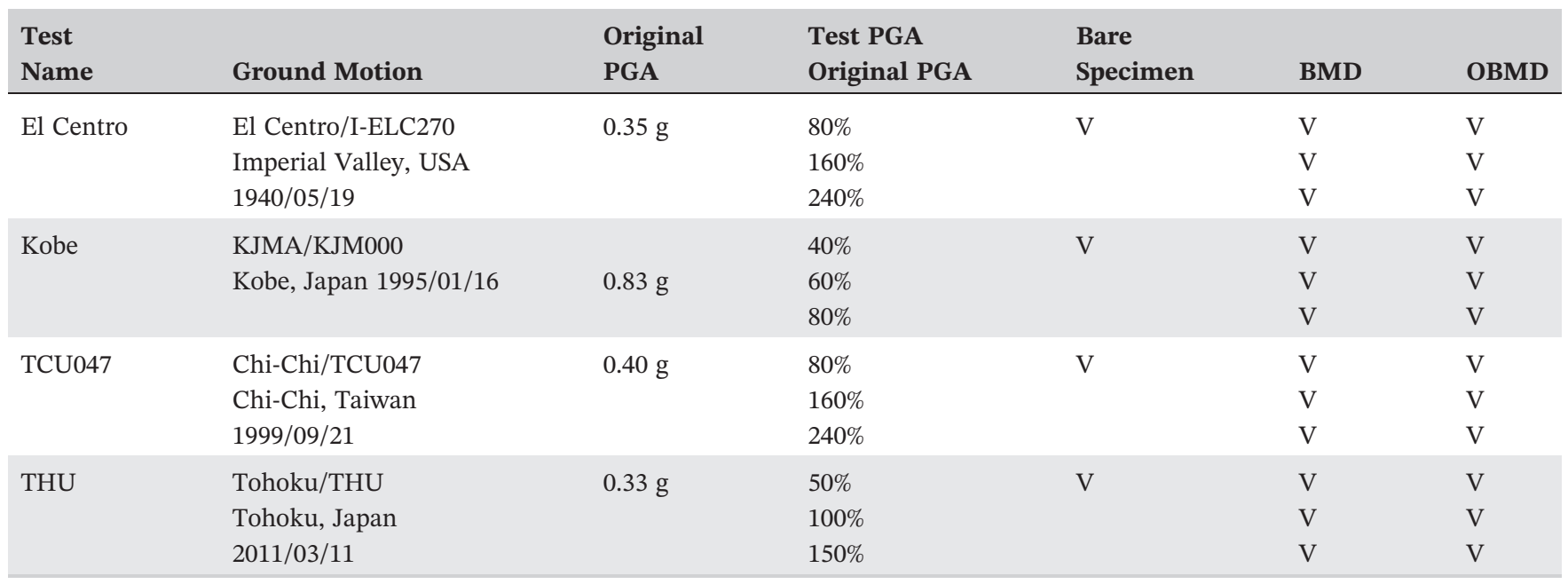

were recorded at I-ELC270, KJM000, TCU047, and THU stations, respectively, during the 1940 El Centro earthquake, the 1995 Kobe earthquake, the 1999 Taiwan Chi-Chi earthquake, and the 2011 Tohoku earthquake (respectively, denoted as El Centro, Kobe, TCU047, and THU thereafter). Among the 4 ground motion records, El Centro and TCU047 are typical far-field ground motions, while Kobe and THU have more long period contents. Besides, THU is a long-duration ground motion. Because the specimens were assumed as a $1 / 4$ scaled structure model, a time scale of $1 / \sqrt{4}$ was considered for the earthquake inputs to meet the similitude law. Note that the maximum test PGA level was determined on the premise of the specimens remaining essentially elastic. The 5\% damped acceleration and displacement response spectra of all the time-scaled ground motions normalized to a PGA value of $1 \mathrm{~g}$ are illustrated in Figure 7. To measure the concerning dynamic responses, accelerometers and displacement transducers were installed on each slab of the specimens. In addition, load cells were installed underneath the base of the specimens as well as between the SUP and SUB of the BMD and OBMD specimens.

\section{3 | Test results}

\subsection{1 | Influence of varying design parameters on seismic performance}

To make a visual and comprehensive comparison, vertical distributions of maximum X-directional acceleration and inter-story displacement responses of all the BMD specimens under the 4 ground motion records with a PGA level are 

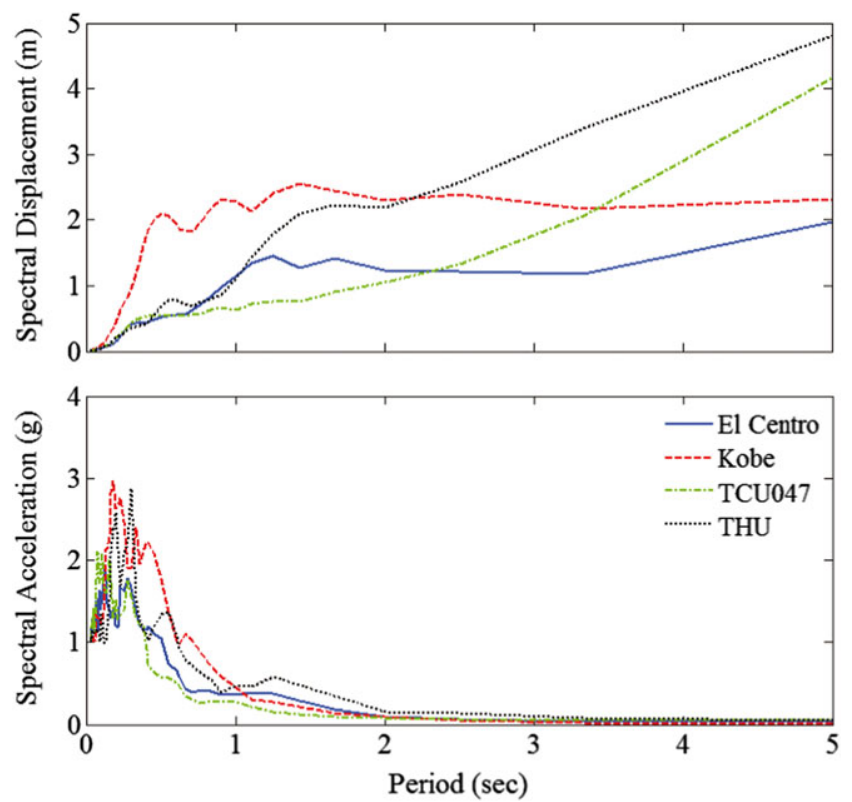

FIGURE 7 5\% damped acceleration and displacement response spectra of time-scaled ground motions with PGA of $1 \mathrm{~g}$ [Colour figure can be viewed at wileyonlinelibrary.com]
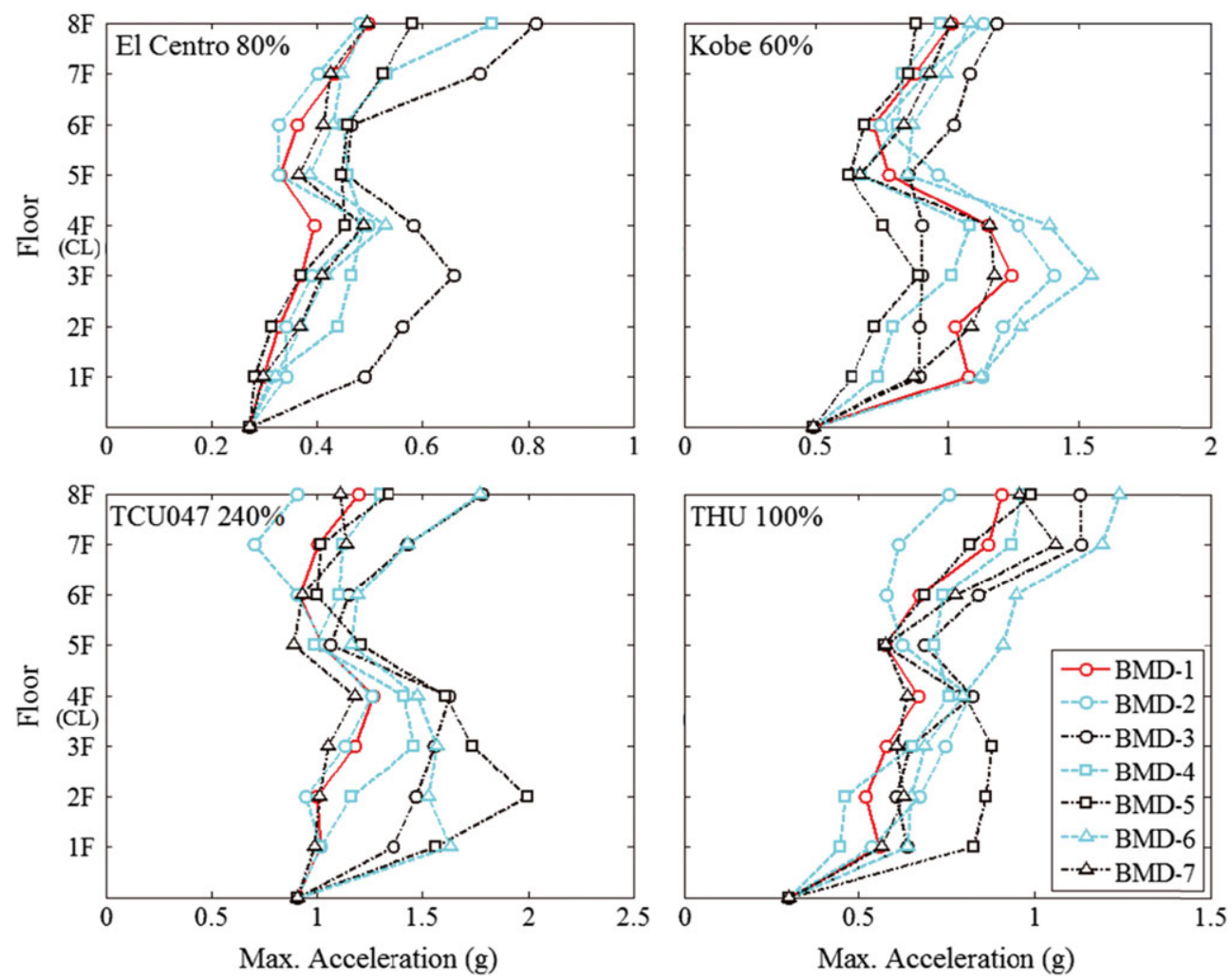

FIGURE 8 Vertical distributions of maximum X-directional acceleration responses of BMD-1, BMD-2, BMD-3, BMD-4, BMD-5, BMD-6, and BMD-7 [Colour figure can be viewed at wileyonlinelibrary.com]

presented in Figures 8 and 9, respectively. The maximum-acceleration ratios $\left(A R_{1}\right)$ and maximum-inter-story-displacement ratios $\left(I D R_{1}\right)$ of BMD-2 to BMD-1 and BMD-3 to BMD-1, as calculated, respectively, in Equations 7 and 8 , at different floors excluding the CL (or $4 \mathrm{~F}$ ) under all the earthquake inputs as listed in Table 3 are shown in Figure 10. Similarly, the maximum-acceleration ratios $\left(A R_{1}\right)$ and maximum-inter-story-displacement ratios $\left(I D R_{1}\right)$ of BMD-4 to BMD-1 and BMD-5 to BMD-1 as well as BMD-6 to BMD-1 and BMD-7 to BMD-1, as calculated, respectively, in 

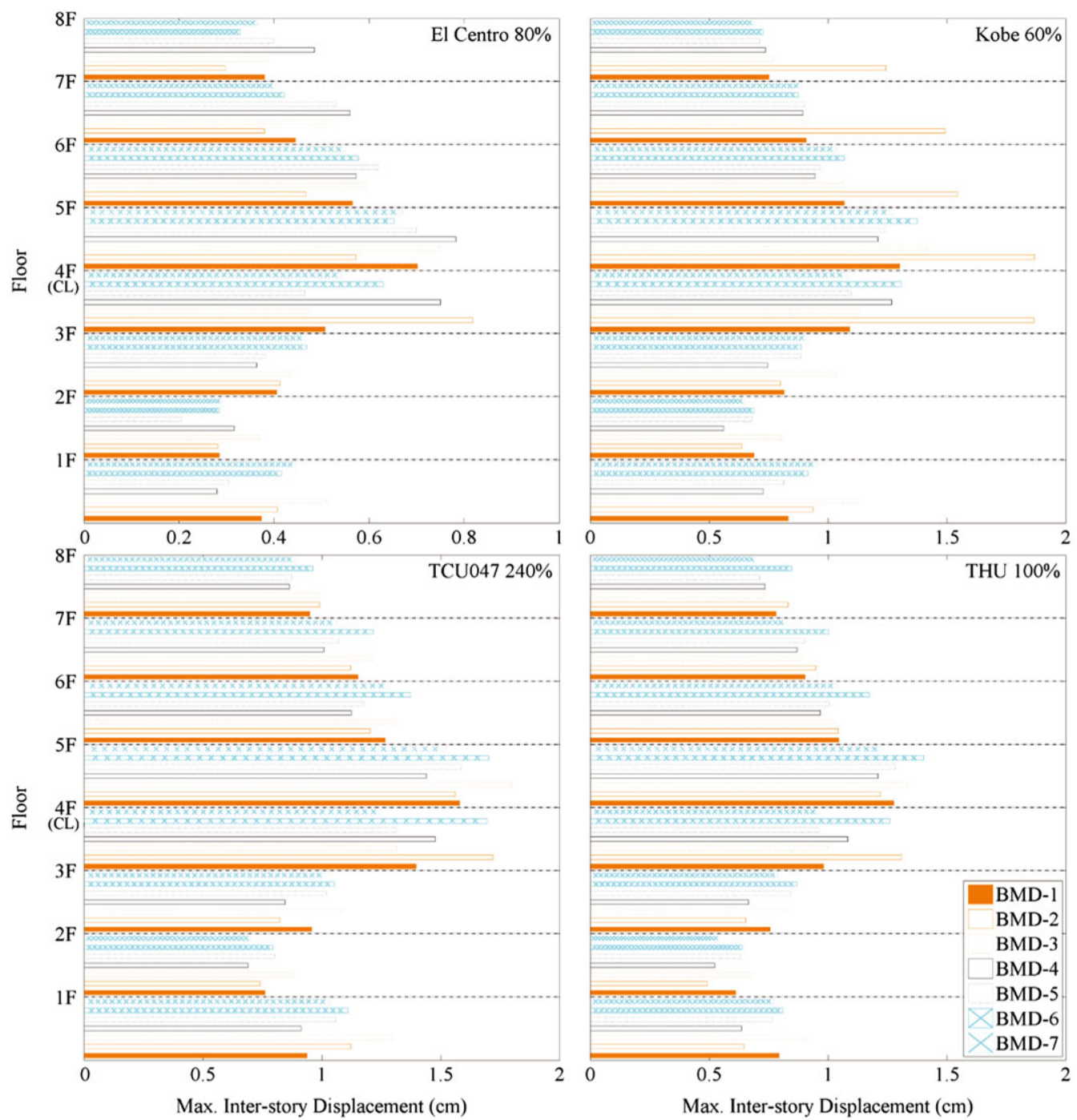

FIGURE 9 Vertical distributions of maximum X-directional inter-story displacement responses of BMD-1, BMD-2, BMD-3, BMD-4, BMD5, BMD-6, and BMD-7 [Colour figure can be viewed at wileyonlinelibrary.com]

FIGURE 10 Maximum-acceleration and maximum-inter-story-displacement ratios of BMD-2 and BMD-3 to BMD-1 at different stories [Colour figure can be viewed at wileyonlinelibrary.com]

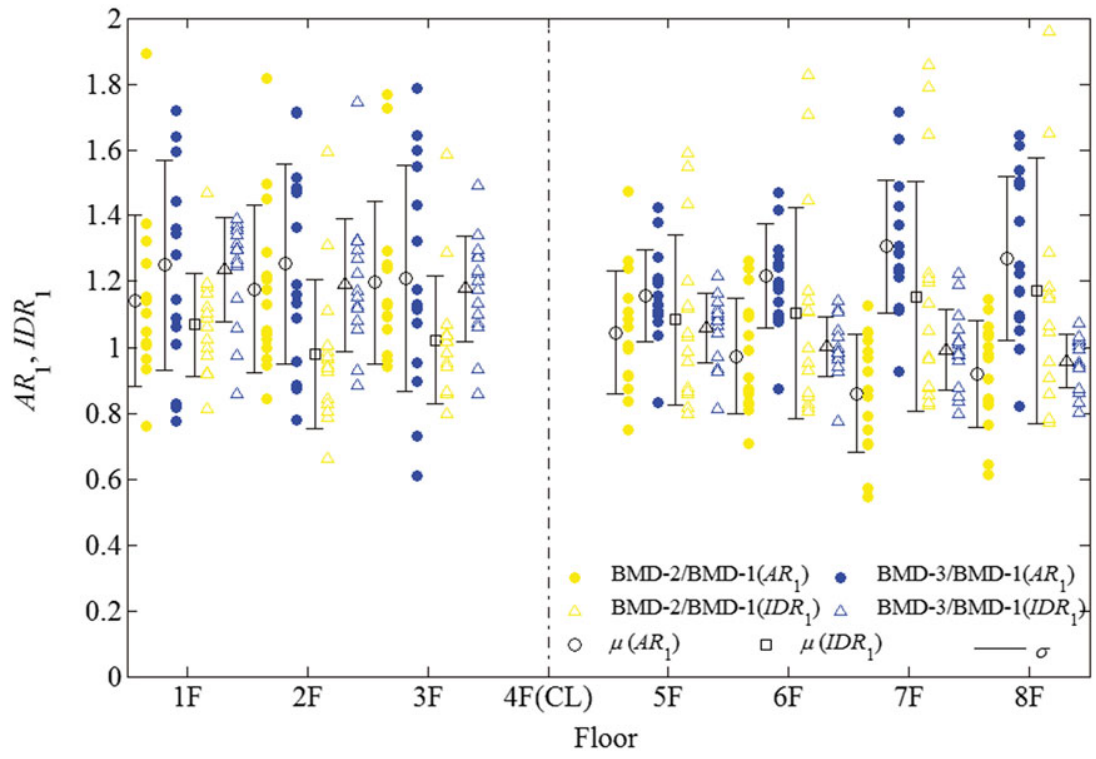


Equations 7 and 8, are shown in Figures 11 and 12. To statistically and overall discuss the influence of varying $f_{2}, f_{3}$, and $\xi_{2}$ on the seismic performance of the BMD specimens, the information of mean $(\mu)$ and standard deviation $(\sigma)$ is also provided in Figures 10--12. For better comparison and realization, the average maximum-acceleration ratios and average maximum-inter-story-displacement ratios of BMD-2 to BMD-1, BMD-3 to BMD-1, BMD-4 to BMD-1, BMD-5 to BMD1, BMD-6 to BMD-1, and BMD-7 to BMD-1 at the 3-story SUB and 4-story SUP under all the earthquake inputs and different ground motion records as listed in Table 3 are shown in Figure 13.

$$
\begin{aligned}
& A R_{1}=\operatorname{Max} A c c_{B M D-i, j} / \operatorname{Max} A c c_{B M D-1, j} \\
& I D R_{1}=\operatorname{Max} I D_{B M D-i, j} / \operatorname{Max} I D_{B M D-1, j}
\end{aligned}
$$

where the subscript $i=2$ to 7 correspondingly represent BMD-2, BMD-3, BMD-4, BMD-5, BMD-6, and BMD-7; the subscript $j$ represents the $j^{t h}$ floor ( $j=1$ to 8); $\operatorname{Max}_{A c c_{B M D-i, j}}$ and $\operatorname{Max} I D_{B M D-i, j}$ represent the maximum X-directional acceleration and inter-story displacement responses at the $j^{\text {th }}$ floor of BMD- $i$ ( $i=2$ to 7), respectively; Max $A c c_{B M D-1, j}$ and Max $I D_{B M D-1, j}$ represent the maximum X-directional acceleration and inter-story displacement responses at the $j^{\text {th }}$ floor of BMD-1, respectively.
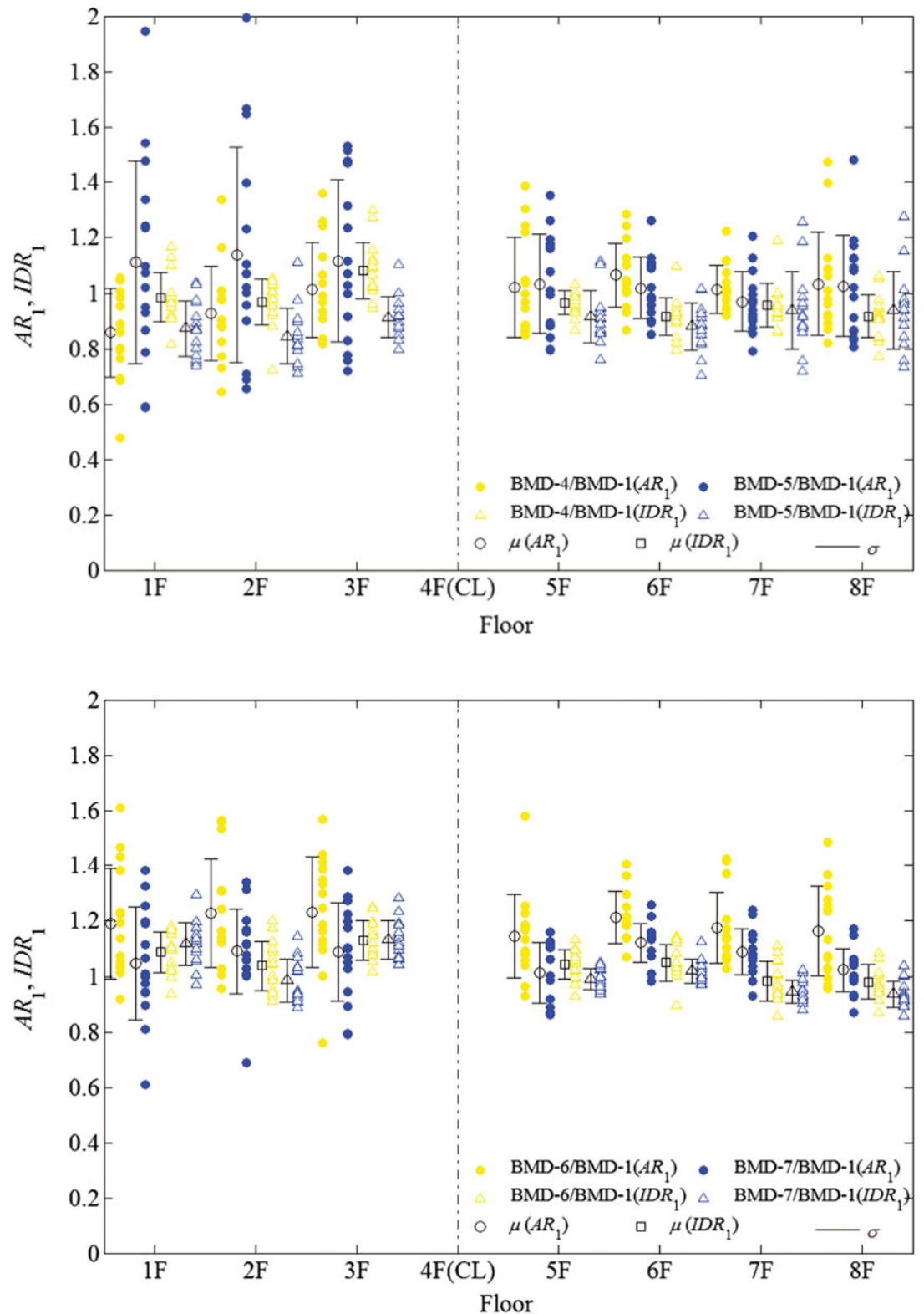

FIGURE 11 Maximum-acceleration and maximum-inter-story-displacement ratios of BMD-4 and BMD-5 to BMD-1 at different stories [Colour figure can be viewed at wileyonlinelibrary.com]

FIGURE 12 Maximum-acceleration and maximum-inter-story-displacement ratios of BMD-6 and BMD-7 to BMD-1 at different stories [Colour figure can be viewed at wileyonlinelibrary.com] 

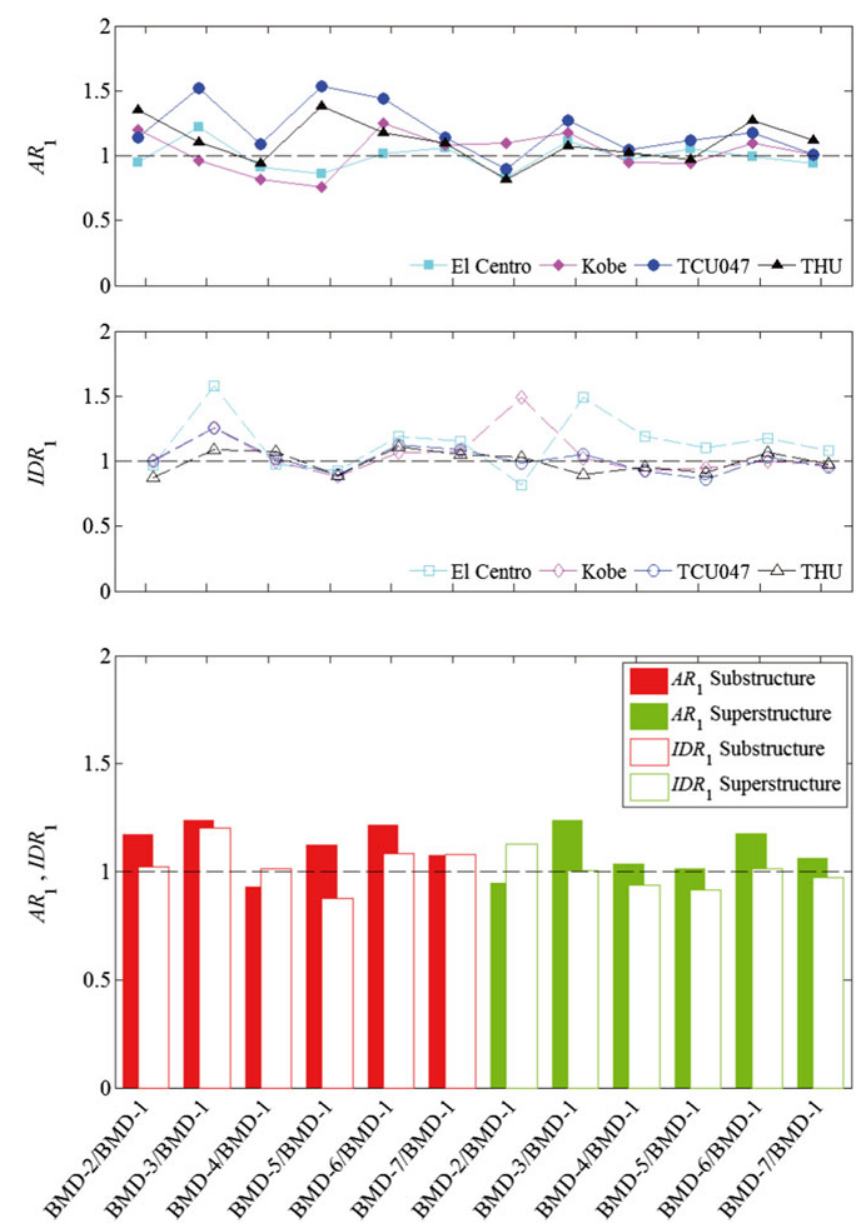

FIGURE 13 Average maximum-acceleration and maximum-inter-story-displacement ratios of all BMD specimens at substructure and superstructure [Colour figure can be viewed at wileyonlinelibrary.com]

As observed from Figures 8, 10, and 13, in general, decreasing $f_{2}$ may cause enlarged acceleration responses at the SUB, which is particularly evident when subjected to Kobe and THU, ie, long-period and long-duration ground motions. Besides, increasing $f_{2}$ may result in enlarged ones at both the SUB and SUP. It is particularly evident when subjected to El Centro and TCU047, ie, far-field ground motions. As observed from Figures 8, 11, and 13, in general, increasing $f_{3}$ may enlarge the acceleration responses of the SUB. It is particularly true while subjected to TCU047 and THU, ie, far-field and long-duration ground motions. As observed from Figures 8, 12, and 13, it is of no surprise that the acceleration responses at both the SUB and SUP of BMD-6 are larger than those of BMD-1 because of its smaller $\xi_{2}$. However, when $\xi_{2}$ becomes very large, eg, $\xi_{2}=35 \%$ in BMD-7, it may not be very helpful and even slightly harmful to the acceleration control performance compared with BMD-1 $\left(\xi_{2}=22 \%\right)$.

As observed from Figures 9, 10, and 13, in general, decreasing $f_{2}$ may cause enlarged inter-story-displacement responses at the SUP, which is particularly evident while subjected to Kobe, ie, long-period ground motions. Besides, increasing $f_{2}$ may result in enlarged ones at the SUB. As observed from Figures 9, 11, and 13, neither decreasing nor increasing $f_{3}$ causes significantly enlarged inter-story-displacement responses at the SUB and SUP. As observed from Figures 9,12 , and 13, the influence of varying $\xi_{2}$ on the inter-story-displacement control at the SUB may be more significant than that at the SUP. Among BMD-1 to BMD-7 under all the earthquake inputs as listed in Table 3, the maximum inter-story displacement response at the CL is $20.5 \mathrm{~mm}$, which is corresponding to a shear strain of $75.93 \%$ for RBs.

\subsubsection{Comparison of seismic responses between bare, building mass damper, and optimum building mass damper specimens}

To make a visual and comprehensive comparison, vertical distributions of maximum X-directional acceleration and inter-story displacement responses of the bare and OBMD specimens under the 4 ground motion records with the 
minimum PGA level are presented in Figures 14 and 15, respectively. To statistically and overall demonstrate that the OBMD specimen designed based on the proposed objective function can have a superior seismic performance to the bare and BMD specimens, the average maximum-acceleration ratios $\left(A R_{2}\right)$ and average maximum-inter-story-displacement ratios $\left(I D R_{2}\right)$ of the bare and BMD specimens to the OBMD specimen, as calculated, respectively, in Equations 9 and 10, at the 3-story SUB and 4-story SUP under all the earthquake inputs and different ground motion records as listed in Table 3 are shown in Figure 16.

$$
\begin{gathered}
A R_{2}=\operatorname{Max} A c c_{B M D-i, j}\left(\text { or } \operatorname{Max} A \operatorname{Ac}_{B a r e, j}\right) / \operatorname{Max} A c c_{O B M D, j} \\
I D R_{2}=\operatorname{Max} I D_{B M D-i, j}\left(\text { or } \operatorname{Max} I D_{B a r e, j}\right) / \operatorname{Max} I D_{O B M D, j}
\end{gathered}
$$

where the subscript $i=1$ to 7 correspondingly represent BMD-1, BMD-2, BMD-3, BMD-4, BMD-5, BMD-6, and BMD-7; Max $A c c_{B M D-i, j}$, Max $A c c_{B a r e, j}$, and Max $A c c_{O B M D, j}$ represent the maximum X-directional acceleration responses at the $j^{\text {th }}$ floor of BMD- $i$ ( $i=1$ to 7), the bare specimen, and the OBMD specimen, respectively; Max $I D_{B M D-i, j}$, Max $I D_{B a r e, j}$, and Max $I D_{O B M D, j}$ represent the maximum X-directional inter-story displacement responses at the $j^{\text {th }}$ floor of BMD- $i(i=1$ to 7$)$, the bare specimen, and the OBMD specimen, respectively. Note that when the ratio is larger than unity and becomes higher, a better control performance of the OBMD specimen can be achieved.

As observed from Figures 14--16, undoubtedly, the seismic performance of the OBMD specimen is much better than that of the bare specimen. In addition, the OBMD specimen in general has a superior potential in reducing seismic responses to the BMD specimens. It is particularly true for the acceleration control performance at the SUP as well as the inter-story displacement control performance at both the SUB and SUP. It is experimentally demonstrated that the proposed optimum dynamic characteristic control approach for the OBMD design is effective and necessary. Under all the earthquake inputs as listed in Table 3, the maximum inter-story displacement response at the CL of the OBMD specimen is only $12.2 \mathrm{~mm}$, which is corresponding to a shear strain of $64.2 \%$ for RBs.
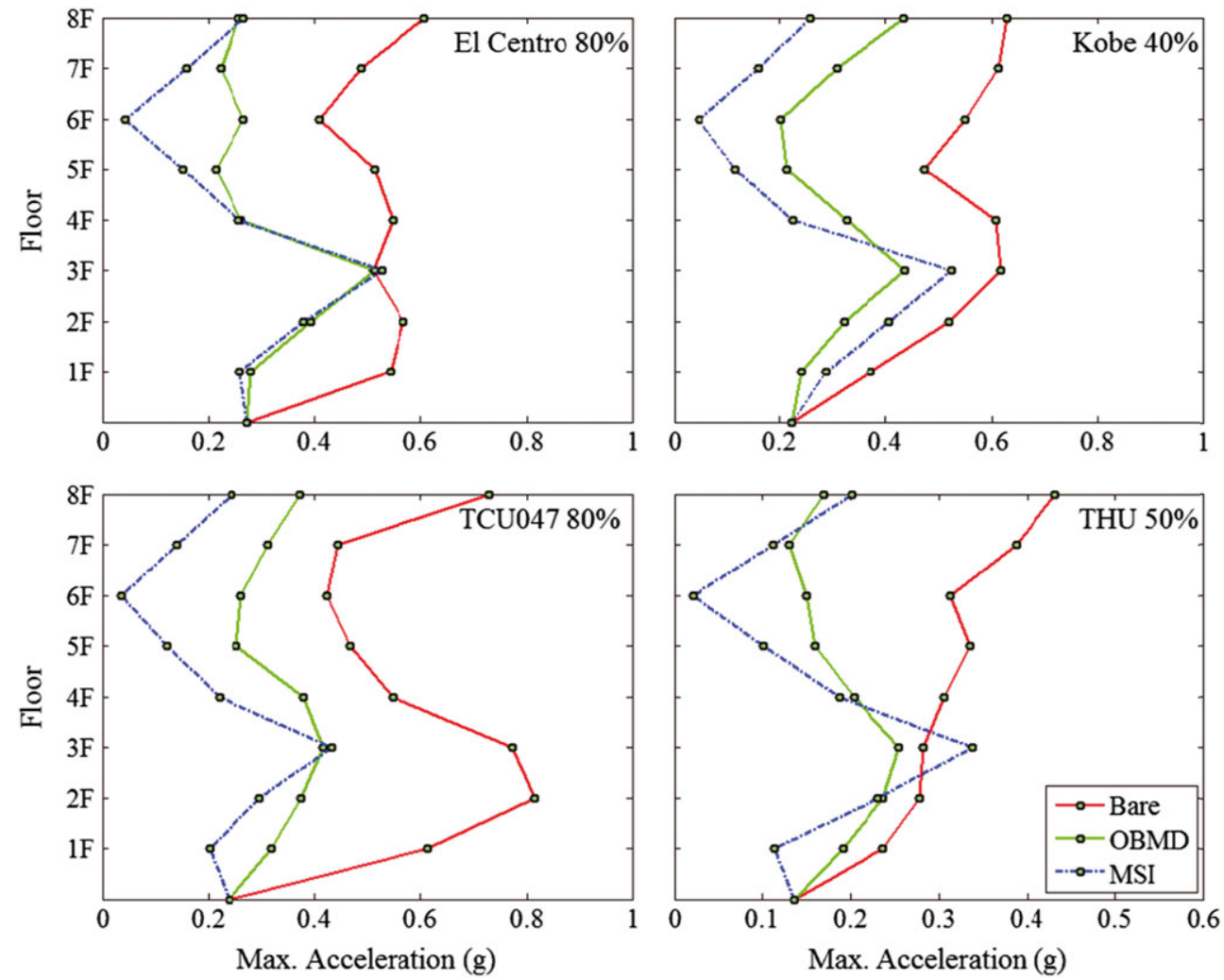

FIGURE 14 Vertical distributions of maximum X-directional acceleration responses of bare and OBMD specimens as well as MSI [Colour figure can be viewed at wileyonlinelibrary.com] 

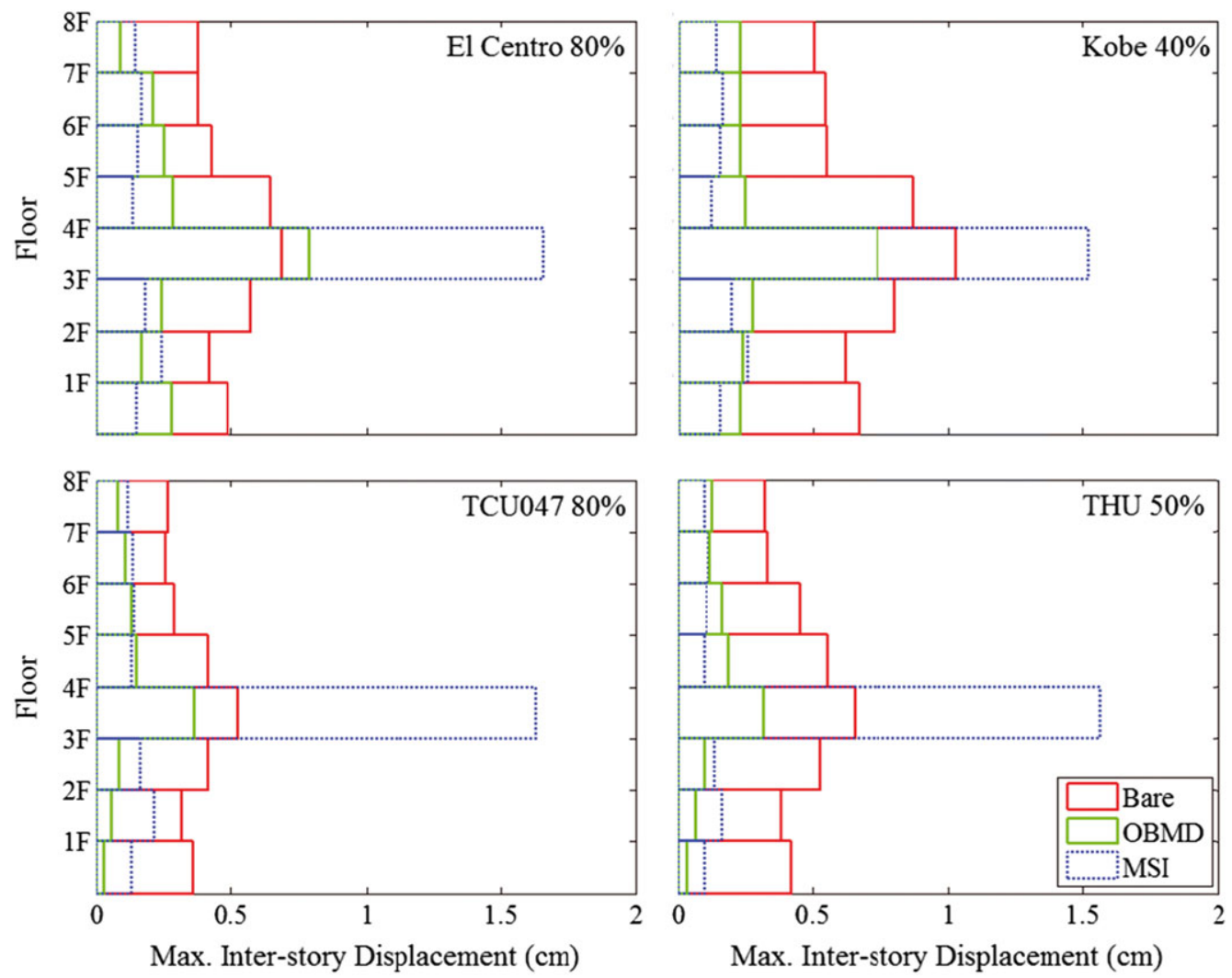

FIGURE 15 Vertical distributions of maximum X-directional inter-story displacement responses of bare and OBMD specimens as well as MSI [Colour figure can be viewed at wileyonlinelibrary.com]

\section{4 | COMPARISON WITH MID-STORY ISOLATION DESIGN}

The seismic performance of the proposed OBMD design is further compared with that of a typical mid-story isolation design in which the seismic isolation system is incorporated into the mid-story rather than the base of the building. As shown in Figure 6D, the same steel structure as the OBMD specimen but designed with a mid-story isolation system composed of different RBs and linear FVDs is numerically built and analyzed. The numerical model designed with a mid-story isolation system is denoted as MSI thereafter. To have a convincing comparison, for MSI, the isolation layer is inserted into the same level as the CL in the OBMD specimen. The force-displacement relationship of a combination of RBs and linear FVDs can be ideally represented by a viscoelastic model. Therefore, considering the same time scale as the test study, ie, $1 / \sqrt{4}$, the isolation period of the SUP as a single degree-of-freedom system is designed to be 1 second. For reasonable comparison, the damping ratio provided by linear FVDs of the mid-story isolation system is designed to be identical to the optimum damping ratio of the OBMD specimen, ie, $\xi_{2}^{o p t}=25 \%$. The design parameters of the RBs and linear FVDs of the mid-story isolation system are detailed in Table 1.

To make a visual and comprehensive comparison, vertical distributions of maximum X-directional acceleration and inter-story displacement responses of MSI under the 4 ground motion records with the minimum PGA level are also presented in Figures 14 and 15, respectively. To statistically and overall compare the seismic performance between the OBMD specimen and MSI, the average maximum-acceleration ratios $\left(A R_{3}\right)$ and average maximum-inter-story-displacement ratios $\left(I D R_{3}\right)$ of MSI to the OBMD specimen, as calculated respectively in Equations 11 and 12, at the 3-story SUB and 4-story SUP under all the earthquake inputs and different ground motion records as listed in Table 3 are also shown in Figure 16

$$
\begin{gathered}
A R_{3}=\operatorname{Max} A c c_{M S I, j} / \operatorname{Max} A c c_{O B M D, j} \\
I D R_{3}=\operatorname{Max} I D_{M S I, j} / \operatorname{Max} I D_{O B M D, j}
\end{gathered}
$$



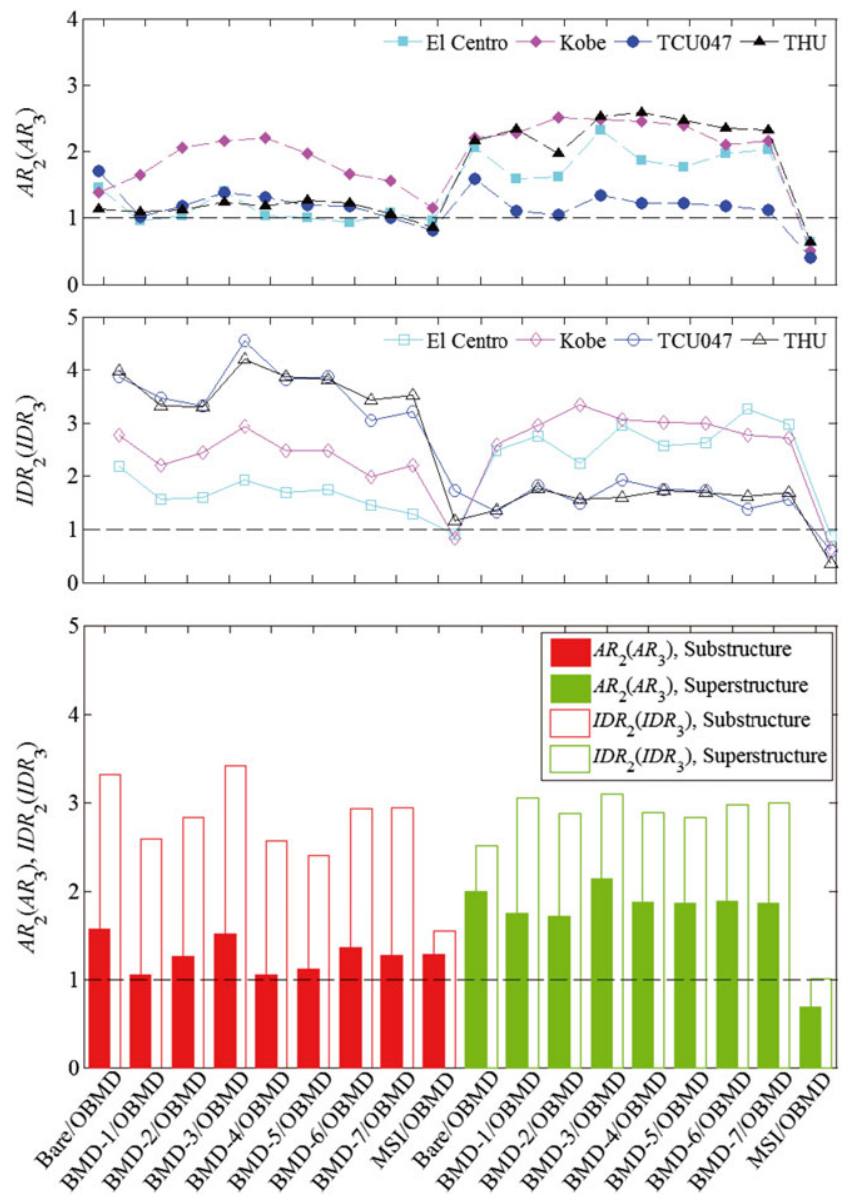

FIGURE 16 Average maximum-acceleration and maximum-inter-story-displacement ratios of bare and BMD specimens as well as MSI to OBMD specimen at substructure and superstructure [Colour figure can be viewed at wileyonlinelibrary.com]

where Max $A c c_{M S I, j}$ and Max $I D_{M S I, j}$ represent the maximum X-directional acceleration and inter-story displacement responses at the $j^{\text {th }}$ floor of MSI, respectively; Max $A c c_{O B M D, j}$ and Max $I D_{O B M D, j}$ represent the maximum $\mathrm{X}$-directional acceleration and inter-story displacement responses at the $j^{\text {th }}$ floor of the OBMD specimen, respectively. Note that when the ratio is larger than unity and becomes higher, a better control performance of the OBMD specimen can be achieved.

As observed from Figures 14--16, both the OBMD specimen and MSI can have an excellent seismic performance. As for the SUP, basically, the OBMD specimen has a comparable control performance to MSI, especially for the inter-story displacement control performance. An insight into the comparison is that the OBMD specimen has a more uniform vertical distribution of maximum acceleration responses at both the SUP and SUB than MSI, while MSI is more uniform for the inter-story displacement control. Even if the acceleration control performance at the SUP of the OBMD specimen may not be as good as that of MSI, it is still very satisfactory compared with the bare specimen. As for the SUB, obviously, the OBMD specimen has a better control performance than MSI. It is particularly evident for acceleration responses while subjected to Kobe, ie, long-period ground motions, and for inter-story displacement responses while subjected to TCU047, ie, far-field ground motions. It is because that the OBMD specimen is designed based on a more comprehensive objective function, while MSI is designed only considering the seismic performance of the isolated SUP. Therefore, in the future study, the proposed optimum dynamic characteristic control approach might also be applied to the mid-story isolation design to effectively solve its response amplification problem at the SUB. ${ }^{4-6}$ The maximum inter-story displacement at the isolation layer of MSI under all the earthquake inputs as listed in Table 3 is $44.7 \mathrm{~mm}$. In general, the inter-story displacement response at the CL of the OBMD specimen is much smaller than that at the isolation layer of MSI. It is indicated that for the proposed OBMD design, some instability concerns due to excessive displacement at the CL can be precluded. 


\section{5 | CONCLUSIONS}

In this study, an OBMD design approach was proposed, and a series of sensitivity analyses and verification tests were conducted. Some conclusions are made as follows.

1. The BMD design, conceptually, is similar to the TMD design but possesses a larger mass ratio and more advantages. The objective function to determine the OBMD design parameters in this study is modified from Sadek's research ${ }^{16}$ and derived based on a simplified 3-lumped-mass structure model. The sensitivity analysis results show a different trend for the optimum damping ratio varying with respect to the mass ratio from Sadek's research and many other past studies, ie, the larger the mass ratio, the lower the damping demand required. Therefore, by means of the proposed optimum dynamic characteristic control approach based on the 3-lumped-mass structure model to design a building with a BMD system, a reasonable and applicable damping demand can be obtained.

2. Shaking table test results indicate that varying design parameters will cause entirely different seismic performances of a building with a BMD system. On the whole, moderately smaller $f_{2}$ and $f_{3}$ as well as larger $\xi_{2}$ can have a better control performance. Undeniably, however, the seismic performance of the BMD design, like the conventional TMD design, is strongly related to the frequency content of seismic excitation.

3. Shaking table test results show that the proposed OBMD design has a superior potential in reducing the seismic responses of both the SUB (or primary structure) and SUP (or tuned mass) to the BMD design, which demonstrates the effectiveness and significance of the proposed optimum dynamic characteristic control approach. Undoubtedly, the seismic performance of the proposed OBMD design is much better than a counterpart without any structural control technology.

4. By comparing with the numerical results of a mid-story isolated counterpart, it is disclosed that the proposed OBMD design can have a comparable and even better control performance. More importantly, in the future study, the proposed optimum dynamic characteristic control approach might also be applied to the mid-story isolation design to effectively solve its response amplification problem at the SUB.

In the future research, another OBMD design approach based on the optimum dynamic response control concept will be investigated. In addition, to further verify the practicability and efficacy of the proposed OBMD design, a practical and realistic building structure will be numerically studied.

\section{ACKNOWLEDGEMENTS}

The study was financially aided by the Ministry of Science and Technology (MOST, 102-2221-E-002-127-) of Taiwan and was experimentally supported by the National Center for Research on Earthquake Engineering (NCREE), National Applied Research Laboratories (NARL), of Taiwan. The support is greatly acknowledged.

\section{ORCID}

Shiang-Jung Wang (iD http://orcid.org/0000-0003-4631-0437

\section{REFERENCE}

1. Nagarajaiah S, Xiaohong S. Response of base-isolated USC hospital building in Northridge earthquake. J Struct Eng ASCE. 2000;126: 1177-1186.

2. Fujita T. Seismic isolation of civil buildings in Japan. Prog Struct Eng Mater. 1998;1(3):295-300.

3. Martelli A, Forni M, Clemente P. Recent worldwide application of seismic isolation and energy dissipation and conditions for their correct use. In: Proceedings of the 15th World Conference on Earthquake Engineering, Lisbon, 2012.

4. Wang SJ, Chang KC, Hwang JS, Hsiao JY, Lee BH, Hung YC. Dynamic behavior of a building structure tested with base and mid-story isolation systems. Eng Struct. 2012;42:420-433.

5. Wang SJ, Hwang JS, Chang KC, Lin MH, Lee BH. Analytical and experimental studies on mid-story isolated buildings with modal coupling effect. Earthq Eng Struct Dyn. 2013;42(2):201-219.

6. Wang SJ, Chang KC, Hwang JS, Lee BH. Simplified analysis of mid-story seismically isolated buildings. Earthq Eng Struct Dyn. 2011;40(2):119-133. 
7. Koh T, Kobayashi M. Vibratory characteristics and earthquake response of mid-story isolated buildings. Mem Inst Sci Technol Meiji University. 2000;39(12):97-114.

8. Li XZ, Ou HL, Lin S. Simplified analysis on calculation model of interlayer seismic isolation. Earthq Eng Eng Vib. 2002;22(1):121-125.

9. Frahm H. Device for damping vibrations of bodies. U.S. Patent No. 989958; 1909.

10. Den Hartog JP. Mechanical Vibrations. 4th ed. NY: McGraw-Hill; 1956.

11. McNamara RJ. Tuned mass dampers for buildings. J Struct Div. 1977;103(9):1785-1798.

12. Luft RW. Optimum tuned mass dampers for buildings. J Struct Div. 1979;105:2766-2772.

13. Warburton GB. Optimal absorber parameters for various combinations of response and excitation parameters. Earthq Eng Struct Dyn. 1982;10(3):381-401.

14. Tsai HC, Lin GC. Optimum tuned-mass dampers for minimizing steady-state response of support-excited and damped systems. Earthq Eng Struct Dyn. 1993;23(11):957-973.

15. Villaverde R. Reduction seismic response with heavily-damped vibration absorbers. Earthq Eng Struct Dyn. 1985;13(1):33-42.

16. Sadek F, Mohraz B, Taylor AW, Chung RM. A method of estimating the parameters of tuned mass dampers for seismic applications. Earthq Eng Struct Dyn. 1997;26(6):617-635.

17. Kwok KCS, Samali B. Performance of tuned mass dampers under wind loads. Eng Struct. 1995;17(9):655-667.

18. Ricciardelli F, Pizzimenti AD, Mattei M. Passive and active mass damper control of the response of tall buildings to wind gustiness. Eng Struct. 2003;25(9):1199-1209.

19. Kaynia AM, Biggs JM, Veneziano D. Seismic effectiveness of tuned mass dampers. J Struct Div. 1981;107(8):1465-1484.

20. Sladek JR, Klingner RE. Effect of tuned-mass dampers on seismic response. J Struct Eng ASCE. 1983;109(8):2004-2009.

21. Pinkaew T, Lukkunaprasit P, Chatupote P. Seismic effectiveness of tuned mass dampers for damage reduction of structures. Eng Struct. 2003;25(1):39-46.

22. Chen G, Wu J. Experimental study on multiple tuned mass dampers to reduce seismic responses of a three-storey building structure. Earthq Eng Struct Dyn. 2003;32(5):793-810.

23. Ziyaeifar M, Noguchi H. Partial mass isolation in tall buildings. Earthq Eng Struct Dyn. 1998;27(1):49-65.

24. Villaverde R. Aseismic roof isolation system: feasibility study with 13-story building. J Struct Eng ASCE. 2002;128(2):188-196.

25. Angelis MD, Perno S, Reggio A. Dynamic response and optimal design of structures with large mass ratio TMD. Earthq Eng Struct Dyn. 2012;41(1):41-60.

26. Kidokoro R. Self mass damper (SMD): seismic control system inspired by the pendulum movement of an antique clock. In: Proceedings of the 14th World Conference on Earthquake Engineering, Beijing, 2008.

27. Gilani ASJ, Miyamoto HK, Mahin S, Nighbor R. Seismic retrofit of the LAX theme building with mass damper: analysis and experimentation. In: Proceedings of the 15th World Conference on Earthquake Engineering, Lisbon, 2012.

28. Kautsky J, Nichols NK, Dooren PV. Robust pole assignment in linear state feedback. Int J Control. 1985;41(5):1129-1155.

How to cite this article: Wang S-J, Lee B-H, Chuang W-C, Chang K-C. Optimum dynamic characteristic control approach for building mass damper design. Earthquake Engng Struct Dyn. 2018;47:872-888. https://doi.org/10.1002/ $\underline{\text { eqe. } 2995}$ 